\title{
A diachronic study of the Mediterranean coastline: A geometric approach
}

\author{
Fatima Zahra Salim*, Mohamed Yassine El Habti, Khadija Ben Hamman Lech-Hab, and Abdelkrim El Arrim \\ Laboratoire «Environnement, Océanologie, et Ressources Naturelles ». Dpt. des Sciences de la Terre, FST de Tanger, Km 9, Route de \\ Ziatine, BP 416, Maroc
}

\begin{abstract}
Coastal areas represent one of the country's most important environmental and economic resources. They are naturally dynamic, with changes that can occur on a human time scale and that need to be quantified for the proper management of shorelines and, in particular, the beaches on which the local economy is largely based. This work focuses on the diachronic study of the coastline of the Mediterranean coast, particularly the coastal fringe at the mouth of the Wadi Aliane. In order to assess and remedy the risks of erosion and accretion of the coastline, the methodology followed consists of the application of automatic analytical techniques using multi-temporal photo-interpretation, a Geographic Information System (GIS) and a Digital Shoreline Analysis System (DSAS). The rate of change will be calculated from the multi-date maps, (1981- 1997 and 2016) using the End Point Rate (EPR) index. Comparison of the results of the interpretation of aerial photos and satellite images of the Oued Aliane coastline used (1981, 1997, and 2016) provided information that allowed us to understand the evolutionary behaviour of the wet sand/dry sand line over 36 years. This numerical analysis of the 1981-1997 and 2016 coastlines in the coastal sector of Oued Aliane, shows us that zones A, C and D are mainly affected by erosion, while the mouth part is affected by accretion because it is considered a delta and therefore a sedimentation area.
\end{abstract}

\section{Introduction}

Morocco benefits from a coastal fringe that stretches over approximately $3500 \mathrm{~km}$ and in two coastal facades, Atlantic and Mediterranean. The Moroccan coastline is the place where all the pressures of economic and demographic development combine and where competition for land is particularly severe [1]. Coastal erosion is a global phenomenon caused largely by two factors: the reduction and sometimes even disappearance of sedimentary inputs to the coast, and eustatic movements. Morocco's coastlines do not escape this erosion. Within the framework of the country's sustainable development, it is essential to take it into account when developing tourism along the coast.

The aim of this article is to understand the role played by anthropogenic developments, particularly offshore dredging, as well as natural factors in the historical evolution of the coastline of the Oued Aliane, and to determine the areas of erosion and accretion. The diachronic study is based on photo-interpretation (aerial photographs, satellite images) and the construction of a geographic information system (GIS) associated with a DSAS Digital Shorline Analysis System and field observations and surveys.

\section{Study area}

The area of Oued Aliane as shown in the figure 1 falls within the rural commune of Ksar Sghir, Fahs Anjra province, which is part of the Tangier-Tetouan-Al Houceima economic region. Oued Aliane is located on the southern shore of the Strait of Gibraltar, between $35^{\circ} 49^{\prime} 45^{\prime \prime}$ North and $5^{\circ} 38^{\prime} 40^{\prime \prime}$ West, with a distance of $20 \mathrm{~km}$ from the east of the city of Tangier towards Sebta.

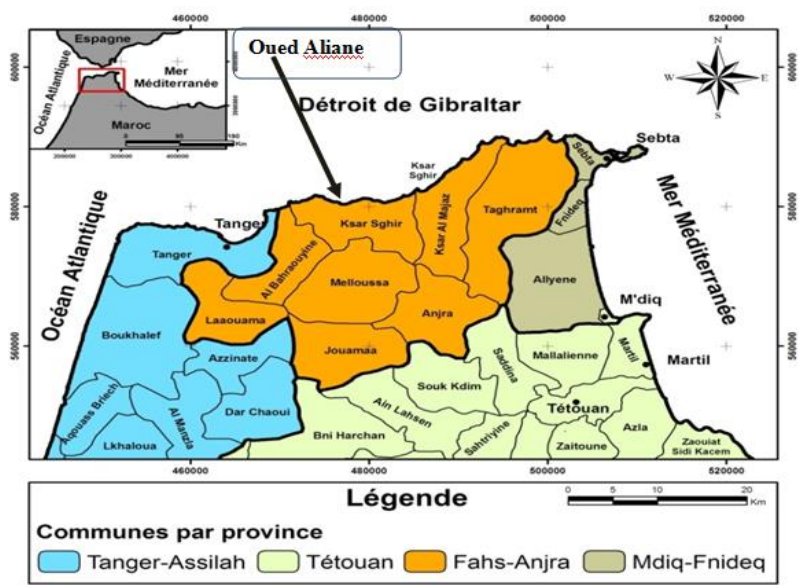

Fig. 1. Geographic location and administrative boundaries of the Study Area (Raissouni 2012).

\footnotetext{
* Corresponding author: s-fati@hotmail.com
} 
It originates in the south in the region of Dhar El Haj and flows through the sandstone and pelitic formations of the Rifain Flysch area until it emerges in the Mediterranean on the southern shore of the strait. The topography of the central part of the Wadi Aliane is rugged. The slope is generally directed towards the Mediterranean or towards the river that runs through the centre (Oued Aliane). The studied area belongs to the rifain domain, more precisely to the external domain and the Flysch domain. The Rif is a recent mountain range, formed in the Tertiary period and made up of allochthonous units carried on the margin of the Africa plate [2]. It first crosses the Beni Ider nappe, which is made up of sandstone and pelitic Flyschs, then, before the mouth, it reaches the Melloussa nappe which appears in the western part and continues until it reaches the sea. The Numidian tablecloth does not appear in the neighborhoods of the Wadi, but it outcrops more to the West or East.

The climate of the commune of Ksar Sghir is of Mediterranean type, with a wet winter and a dry summer. The climatological data of the centre of the wadi Aliane are those of the station of Tangier, the closest station to the centre in the region. The climate of Tangier is both Mediterranean and Atlantic. The Tangier area is characterized by a humid and mild climate. Indeed, the average annual temperature is above $18^{\circ} \mathrm{C}$ and the region has an average rainfall of over 600 $\mathrm{mm} /$ year, one of the highest in the country. Average annual evaporation in the study area is around $1983 \mathrm{~mm}$. Easterly or westerly winds are frequent, with an average speed of 7 to $20 \mathrm{~km} / \mathrm{hr}$. The watershed of Wadi Aliane, draining an area of 12,139.06 ha, is located in the central northern part of the Tingitane Peninsula, Wadi Aliane is characterized by a relatively low flow. A few kilometres before its mouth, an alluvial plain, increasingly widened towards the downstream, limits the bed of the Wadi on both sides. Wadi Aliane presents different units, namely deposit banks, erosion banks, meanders, and an estuarine type mouth that presents the formation of a sandy spit. Groundwater resources, which can be mobilized at the level of the rural commune of Ksar Sghir, are essentially springs, wells and boreholes. The Aliane wadi centre is the seat of an alluvial water table: the Aliane water table. The point in front of the site is in a zone of weakening swell, especially for swells of Atlantic origin. The hydrology of this sea shows that the dominant currents in the Strait of Gibraltar are of different densities : One entering from the Atlantic Ocean and which is less dense at the surface to a thickness of $125 \mathrm{~m}$, the other exiting in parallel and which is denser over a depth of more than $200 \mathrm{~m}$. The tide is of semi-diurnal type, the two full and low seas of each day are almost equal in height.

\section{Equipment and methods}

The methodology used in this research is based on classical digital geographic information processing techniques widely approved in coastal kinematics, described by several authors [3] and [4]. The methodological approach that enabled us to extract the reference lines from the documents selected to observe and analyse the spatio-temporal evolution of the sandy coastline of the Wadi Aliane region at the regional and local scales is based on the following steps: The selection of a reference line adapted to the study area and the type of documents used; the geometric rectification of the available data; the extraction of the selected reference lines then photo-interpretation and finally the determination of the rate of change of the coastline.

\subsection{Basic data}

The study of the kinematics of the coastline is carried out by photo-interpretation from two aerial photographs $(1981,1997)$ as shown in the figures 2 and 3 , and a satellite image (2016) (Figure 4), the scales are between $1 / 17500$ and $1 / 20000$, covering a period of 36 years, the table 1 shows the main characteristics of the aerial photos and satellite image used. Thus, several dates are often recommended to better assess the temporal evolution of the coastline and the accuracy of the calculation of the rate of change increases with the number of coastlines used [5]. Also, a topographic map of Ksar Sghir 1/50 000th (1966) was used in the presence of cross-breaks.

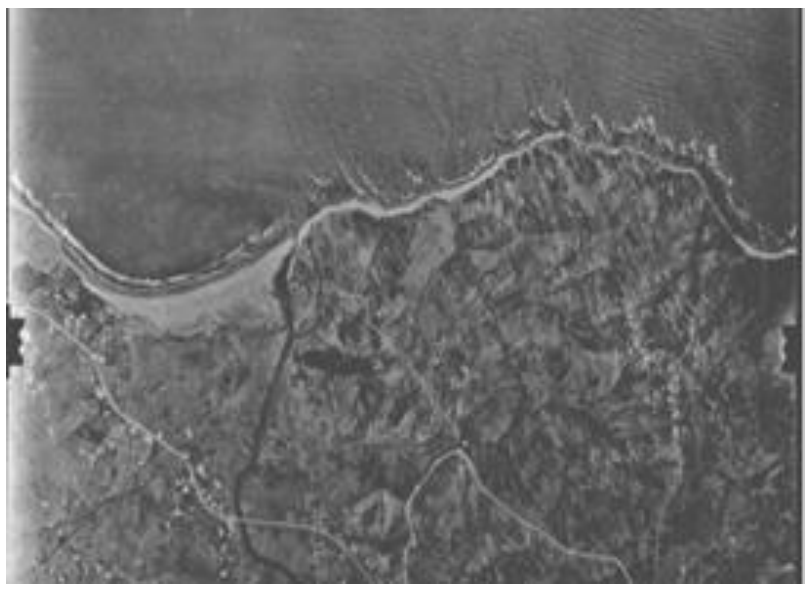

Fig..2. Aerial photograph of the coast of Oued Aliane in 1981

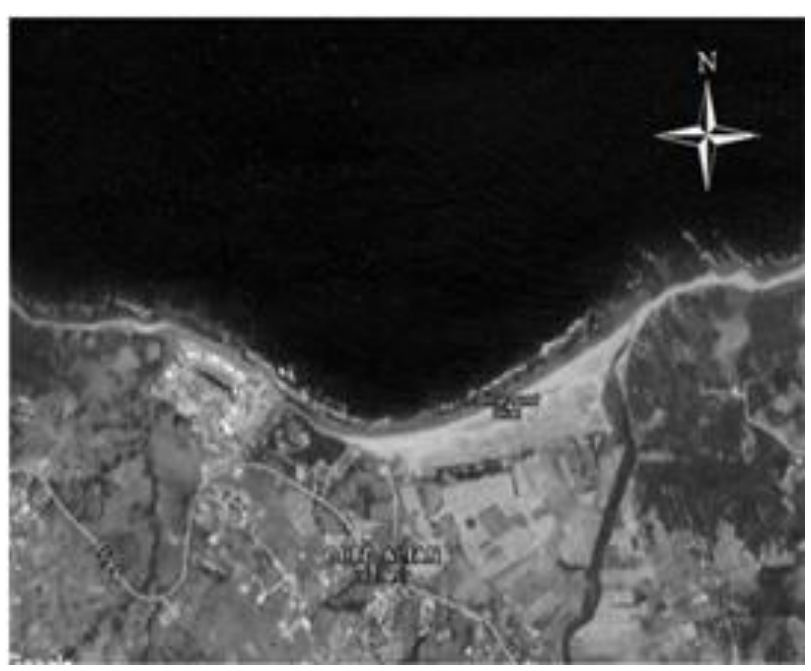

Fig. 3. Mosaic of 2 aerial photographs of the coastline of Oued Aliane in 1997 


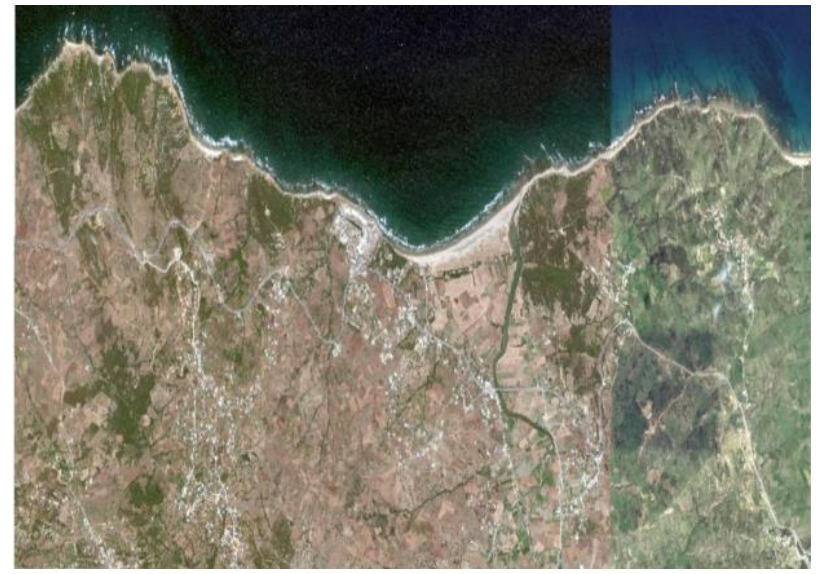

Fig. 4. Satellite image of the coastline of Oued Aliane in 2016

Table 1. Aerial photos and satellite image used characteristics

\begin{tabular}{|l|c|c|c|c|}
\hline Date & Scale & $\begin{array}{l}\text { Pixel } \\
\text { size } \\
(\mathbf{m})\end{array}$ & $\begin{array}{l}\text { Image } \\
\text { Type }\end{array}$ & $\begin{array}{l}\text { Number } \\
\text { of aerial } \\
\text { photo or } \\
\text { satellite } \\
\text { image } \\
\text { used }\end{array}$ \\
\hline $06 / 05 / 1981$ & $1 / 17500$ & $1 \mathrm{~m}$ & $\begin{array}{l}\text { Black \& } \\
\text { White }\end{array}$ & 1 \\
\hline $02 / 08 / 1997$ & $1 / 20000$ & $0.37 \mathrm{~m}$ & $\begin{array}{l}\text { Black \& } \\
\text { White }\end{array}$ & 2 \\
\hline $01 / 02 / 2016$ & $1 / 20000$ & $0.24 \mathrm{~m}$ & Colour & 6 \\
\hline
\end{tabular}

\subsection{Software and tools used}

The software used is: ArcGis 10.5, GIS processing and mapping software with its multiple extensions; DSAS 4.3.4, a GIS application for ArcGIS 10.5, and finally Google Earth Pro which supports GIS data import, high resolution printing (up to 4800 pixels) and area measurement.

\subsection{Methodology for the study of coastline kinematics}

\subsubsection{Choice of the reference line}

It is necessary to choose and extract a line common to the different images used for a diachronic study based on photo-interpretation [6]. The inventory and description of the main shoreline indicators found in the photographs and image from 1981 to 2016 allow the reference line selected for the diachronic analysis to be identified by elimination.

\subsubsection{Detection of coastline identification indicators}

For this purpose, we selected the indicators best suited to reconstructing the kinematics of the sandy coasts of the Oued Aliane. On aerial images from 1981 to 2016, two entities are identifiable: the instantaneous shoreline and the open sea line. In short, the instantaneous shoreline is present in all the images. However, it is not usable because no information is available on the dates and times of the shots and the corresponding tidal heights to make the necessary corrections. Also, there are many difficulties in tracing the coastline in rocky areas. In these conditions, the reference line chosen was Wet sand/dry sand limit or wet limit: at rising tide it is the maximum limit of the run-up, at falling tide it is the part of the beach which is always wet.

\subsubsection{Elaboration and processing of the input data}

The geo-referencing was carried out using ArcGis software. For the geo-referencing of the topographic maps, we first located the location of the different crossings used for the wedging, then we entered the real coordinates in meters of the control point. We did the same work for at least 3 other calibration points for an acceptable accuracy. Finally, and before recording the geo-referenced map, we defined the projection system to which our zone belongs, which is the Lambert conformal conic projection system (North Morocco Lambert I). Regarding the georeferencing of the aerial photos and the image, we based ourselves on the previously georeferenced topographic map. The image is therefore superimposed on the map, georeferenced and ready for use in the following actions.

\subsubsection{Geometric correction}

It is necessary to look for a deformation model that will allow to correct the defects and to bring the images into conformity since the aerial photographs are of different scales and affected by numerous deformations making their geometry imperfect [4], [7 - 11].

a- Mosaic of aerial photos.

b- Photo-interpretation and digitization of reference lines: The visual interpretation and digitization of reference lines on aerial images were performed using ArcView GIS software (ArcGis 10.5). According to [12], the photo-interpretation process is based on three phases: object recognition; analysis and interpretation leading to the identification of the observed objects; and finally the synthesis of the information by modeling the contours of the object(s) sought.

c- Uncertainties, estimation of errors affecting the reference lines: The rates of evolution of a coastline obtained always include a certain amount of uncertainty that must be evaluated to judge the degree of representativeness of the results and to use them properly [11]. [8], [10] and [13] estimate that the overlay of terrestrial features observed in aerial photographs and on a map at this scale can result in an error of \pm 10 metres relative to reality. The RMS errors for each image were greater than or equal to $0.22 \mathrm{~m}$ (Table 2). However, [14] estimates that this error must be reduced to $\pm 1 \mathrm{~m}$, when comparing two images that are aligned with each other, (Table 3 ). 
Table 2. RMS errors related to image rectification

\begin{tabular}{|l|l|l|}
\hline Shooting dates & $\begin{array}{l}\text { Number of } \\
\text { calibration } \\
\text { points }\end{array}$ & RMS error (m) \\
\hline 1981 & 4 & 0.22 \\
\hline 1997 & 4 & 0.37 \\
\hline 2016 & 4 & 0,25 \\
\hline Average & 0,29 \\
\hline
\end{tabular}

Table 3. Estimated overall margin of error

\begin{tabular}{|l|l|}
\hline Error category & Estimated value \\
\hline $\begin{array}{l}\text { Errors in the determination of } \\
\text { reference points }\end{array}$ & \pm 10 \\
\hline $\begin{array}{l}\text { Measurement errors on } \\
\text { corrected aerial photographs }\end{array}$ & \pm 1 \\
\hline Global error & 0.13 \\
\hline
\end{tabular}

\subsection{Tool for measuring and statistically calculating coastline evolution}

The choice of a technique depends on several factors: The data used, the coastline chosen and the accuracy required through such a study [4] and [15]. In the present work, the linear changes were measured automatically using the Geographic Information System (GIS) using the program Digital Shoreline Analysis System (DSAS, version 4.2), which is a module of ArcGIS 10. 5 (ESRI, Redlands, California) developed by US Geological Survey [16], following transects perpendicular to the lines to be compared, generated from a baseline, the DSAS measures the distances between the points of intersection of the transects and the coastlines, calculates the rates of change along each transect and outputs the results in the form of attribute tables. Subsequently, all generated transects were checked to verify and eliminate outliers or those located in areas where baselines could not be digitized and in areas where the quality of georeferencing was poor. The estimation of shoreline kinematics and the mapping of change rates are based on the analysis of automatically generated attribute tables.

To apprehend the temporal evolution of the coastline position, we chose the index proposed by the DSAS: the EPR (End Point Rate) index to evaluate the evolution between the locations of two successive coastlines in order to estimate the evolution rates of each site over the whole study period. It is the ratio of the distance between the oldest and the most recent coastline over time (number of years elapsed between the two dates.) Expressed in metres/year, this attribute is found in the map model under the label "annual average". The PRA is appropriate when two coastlines are available to assess shoreline kinematics [16]. In this study, transects are generated every $50 \mathrm{~m}$ to finely represent the evolution of the coastline and to highlight different aberrations (erosive transect in an accreting zone or vice versa). Statistical calculations of the evolution of the coastline are carried out on all the transects. Then, a mapping work is carried out under ArcGIS 10.5 to interpret the results.

\section{Results and discussion}

The result represents a synthesis of the coastal changes that have occurred since the 20th century in the coastline of Oued Aliane extending over a cumulative coastal line of almost $10 \mathrm{~km}$. The comparison of the results of the interpretation of the aerial images used $(1981,1997$, and 2016) provided information that allowed us to understand the evolutionary behaviour of the wet sand/dry sand line over 36 years. They show a progressive general evolutionary trend along the $10 \mathrm{~km}$ of coastline studied. Indeed, out of the 350 transects analysed, $255(72.92 \%)$ are in erosion and 95 (27.08\%) are in Accretion.

Coastline Mobility (EPR): The study area was divided into 4 sectors from East to West:

Sector A: Rock Zone 1 shown in the figure 5: Spreading over a length of about $2.12 \mathrm{Km}$, the line has been eroded by an average of $-8.05 \mathrm{~m}$ compared to its 1981 situation, i.e. an average erosion rate of -0.23 $\mathrm{m} /$ year (with a maximum of $1.88 \mathrm{~m} /$ year and a minimum of $-3.88 \mathrm{~m} /$ year).

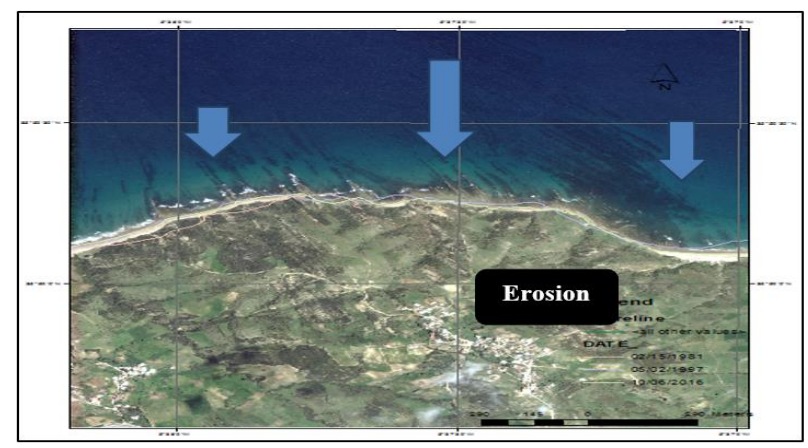

Fig. 5. Sector A: Rock Zone 1

Sector B: The mouth of the catchment area in the figure 6: About $2.24 \mathrm{~km}$ long. It presents an accretion of the coastline: $26.25 \mathrm{~m}$ on average compared to its 1981 situation, i.e. an average erosion rate of $0.75 \mathrm{~m} /$ year (with a maximum of $5.11 \mathrm{~m} /$ year and a minimum of -1.5 $\mathrm{m} /$ year).

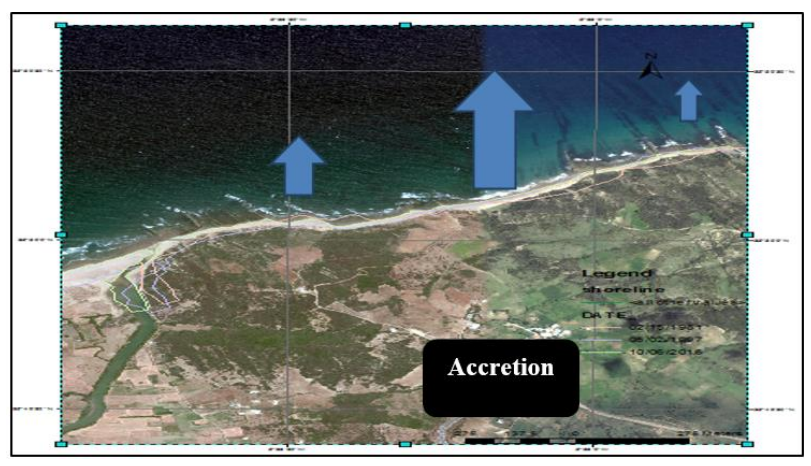

Fig. 6. Sector B: The mouth of the catchment area

Sector C: The figure 7 shows the sandy beach, extending over a length of about $2 \mathrm{Km}$, the line has been eroded by an average of $-44.8 \mathrm{~m}$ compared to its 1981 situation, i.e. an average erosion rate of $-1.28 \mathrm{~m} / \mathrm{year}$ (with a max of $1.09 \mathrm{~m} /$ year and min of $-2.52 \mathrm{~m} /$ year). 


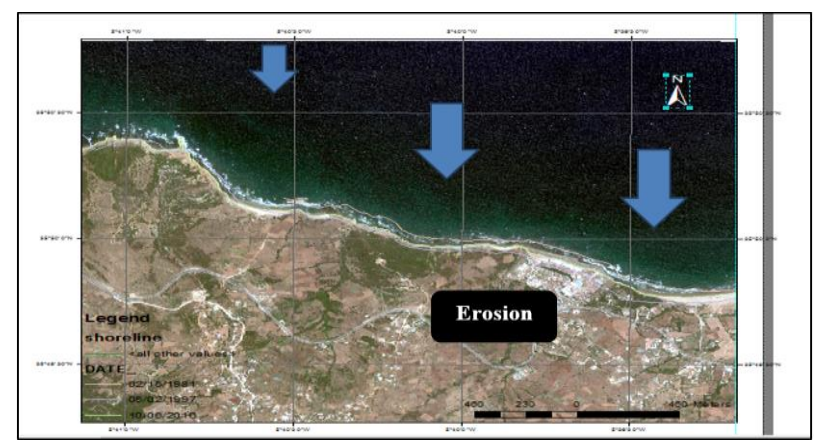

Fig. 7. Sector C: The sandy beach

Sector D: Rocky zone 2: Located to the west of the studied coast as it is shown in the figure 8 , with a length of about $2.84 \mathrm{~km}$, the line has been eroded on average $17.85 \mathrm{~m}$ compared to its 1981 situation, i.e. an average erosion rate of $-0.51 \mathrm{~m} /$ year (with a max of $7.94 \mathrm{~m} /$ year and $\min$ of $-5.71 \mathrm{~m} /$ year).

Based on the results of the numerical analysis of the $1981-1997$ and 2016 coastlines in the coastal sector of Oued Aliane, it can be seen that zones A, C and D are mainly affected by erosion, while the mouth part is affected by accretion because it is considered a delta and therefore a sedimentation area. From the point of view of the reliability of the calculated evolution rates [17], the best match is found in the extreme point method (EPR) since the points are closer to the diagonal. Indeed, this method is more correct in rocky areas where identification of the chosen reference line is difficult. Table 4 resumes the different statistics given by the EPR. While the figure 9 illustrates a map model based on the PRA calculation: The extreme point method for a study period with three Dates.

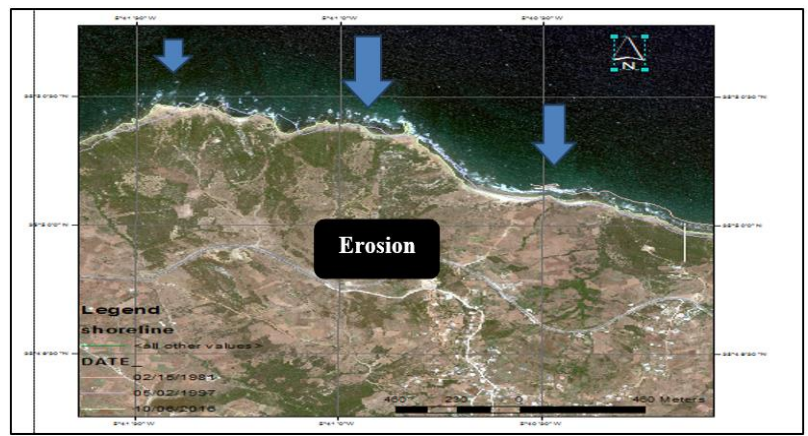

Fig. 8. Sector D: Rocky zone 2

Table 4. The different statistics given by the EPR.

\begin{tabular}{|c|c|c|c|c|c|c|}
\hline \multicolumn{2}{|c|}{ Studied areas } & Sector A & Sector B & Sector C & Sector D & $\begin{array}{l}\text { Oued Aliane } \\
\text { coastline (total) }\end{array}$ \\
\hline \multicolumn{2}{|c|}{ Number of transects } & 90 & 65 & 95 & 100 & 350 \\
\hline \multicolumn{2}{|c|}{ Length $(\mathrm{Km})$} & 2,12 & 2,24 & 2 & 2,84 & 9,2 \\
\hline \multirow{5}{*}{ EPR } & average coastal mobility (m/year) & $-0,23$ & $+0,75$ & $-1,28$ & $-0,51$ & $-1,27$ \\
\hline & $\begin{array}{l}\text { minimum coastal } \\
\text { mobility }(\mathrm{m} / \mathrm{year})\end{array}$ & $-3,88$ & $-1,5$ & $-2,58$ & $-5,71$ & $-13,67$ \\
\hline & $\begin{array}{l}\text { maximum coastal } \\
\text { mobility }(\mathrm{m} / \mathrm{year})\end{array}$ & 1,88 & 5,11 & 1,09 & 7,94 & 16,02 \\
\hline & $\begin{array}{l}\text { total number of transects with } \\
\text { erosin recorded }\end{array}$ & 47 & 13 & 88 & 52 & 255 \\
\hline & $\begin{array}{l}\text { total number of transects with } \\
\text { accretion recorded }\end{array}$ & 43 & 52 & 7 & 48 & 95 \\
\hline
\end{tabular}

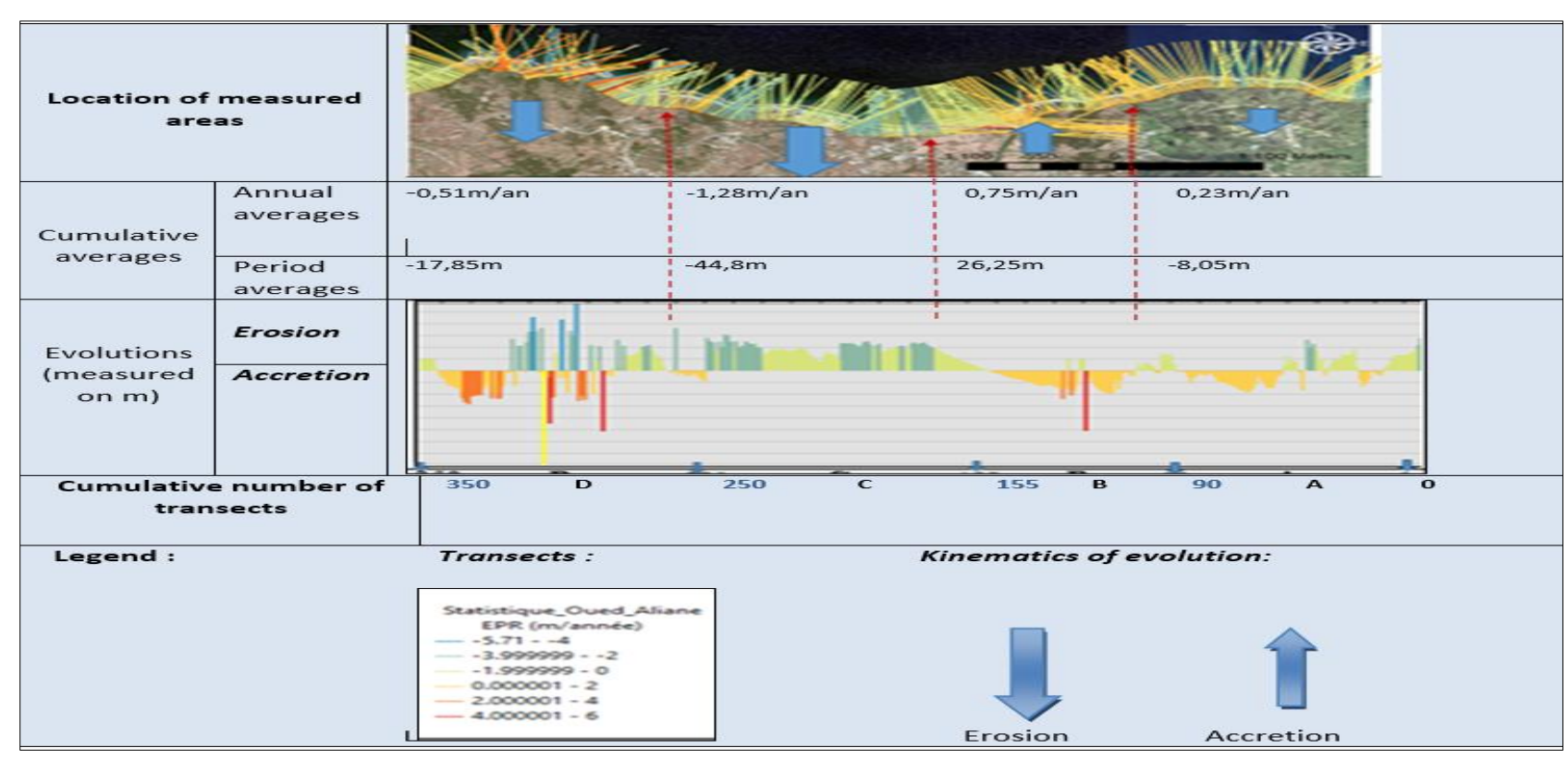

Fig. 9. Map model based on the PRA calculation: The extreme point method for a study period with three Dates. 
These results could be linked to the dominance of natural causes such as swell, especially for swells of Atlantic origin, whereas the whole area to the west is subject to much greater swell action. Another natural factor would be the hydrology of this sea, which shows that the dominant currents in the Strait of Gibraltar have different densities: One is entering from the Atlantic Ocean and which is less dense and on the surface to a thickness of $125 \mathrm{~m}$, the other leaving in parallel and is denser over a depth of over $200 \mathrm{~m}$. On the other hand, the anthropogenic effect is quite apparent in the last 10 years.

\section{Conclusion}

In the Atlantic and Mediterranean, erosive phenomena threaten the coastline. The Moroccan coastline is no exception: due to its complex and vulnerable geographical position, it is under increasing pressure. Its management has proved its limits and has only accentuated the various problems.

This research, like the one carried out on the Bay of Tangier [18], focuses on the constructive and useful function of GIS through the Arcgis software and its DSAS extension, for the study of the case of Oued Aliane beach. The use of photo-interpretation and aerial photography allowed us to study the diachronic kinematics of the coastline. Its interpretation makes it possible to determine the main factors that cause erosion and shows the impact of dredging in the last 10 years on the modification of the morphology of Oued Aliane beach. While natural causes are always obvious, such as swell, wind, currents, tides... Human activity in both researches is increasingly influencing the profile of the beaches.

There are thus several erosion factors directly linked to man: Urbanization of the coastline returns the swell and prevents the waves from breaking, the construction of harbours (e.g. Port Med) prevents the movement of sediment along the coast, The poor design of defense works which by fighting locally on a problem displace it to neighboring beaches, the construction of dams reduces solid inputs from rivers flowing into the sea, the over-use of certain beaches, which deteriorates the dune massifs and finally the degradation of marine plants that slow coastal erosion by stabilizing the seabed and dissipating wave energy.

In a national and international context of growing environmental awareness, Morocco must find the conditions for more "sustainable" development and an integrated approach capable of coordinating the multiple and interdependent interests of all sectors, while respecting environmental values.

\section{References}

1. A. Hilal, L'espace littoral marocain entre pressions du présent et exigences de l'avenir : Cas du littoral d'Essaouira (Maroc). Cinq Continents 6 (13), pp. 79-100 Vol.6 / Numéro 13 Été 2016 ISSN: 2247 2290 p. $79-10$ (2016).
2. 2. A. El Arrim.. Contribution à l'étude du littoral de la baie de Tanger (Rif Nord Occidental-Maroc). Approches sédimentologique, géochimique et impact de la dynamique sédimentaire. Thèse de Doctorat, Univ. Abdelmalek Essaadi, Fac. Sci. Techn. Tanger, 150 p. ( 2001).

3. R. El Hamzaoui., A. Raissouni, A. El Arrim, L'apport de la géomatique dans la gestion des zones côtières. Application d'un SIG côtier (Rif Nord occidental, Maroc). (2011).

4. M. Shoshany, A. Degani ,. Shoreline detection by digital image processing of aerial photography. J. Coast. Res. 8(1), 29-34. (1992)

5. L.J. Moore, Shoreline mapping technics. Journal of Coastal Research, 16 : 111-124. (2000)

6. K. Appeaningaddo, M. Walkden, J.P. Mills, Detection, measurement and prediction of shoreline recession in Accra, Ghana. ISPRS Journal of Photogrammetry and Remote Sensing, 63: 543-558 (2008)

7. I.B.N.D Faye, A. Henaff, F. Gourmelon, E. Giraudet , Cartographie normalisé de l'évolution de trait de côte. (2011)

8. D.B. Stafford, J. Langfelder,. Air photo survey of coastal erosion. Photogrammetry Engineering, 37: 565-575. (1971)

9. R. Dolan, BP Hayde, P. May, S. May The reliability of shoreline change measurements from aerial photographs. Shore Beach 48: 22-29. (1980)

10. F.J. Anders, M.R. Byrnes, Accracy of shoreline changerates as determined from map and aerialphotographs. Shore and Beach, vol.59, ${ }^{\circ} 1, p$. 17-26. (1991)

11. M. Crowell, S. Leatherman, M.K Buckley, Historical shoreline change: Error analysis and mapping accuracy. Journal of Coastal Research, vol.7, p. 839-852. (1991)

12. E.R. Thieler, W.W. Danforth, Historical shoreline mapping (I): Improving techniques and reducing positioning errors. Journal of Coastal Research, vol.10, $n^{\circ} 3$, p. 549-563. (1994a)

13. Provenchier, Dubois, Précis de télédétection Tome 4 Méthodes de photointerprétation. (2007)

14. I.B.ND. Faye, A. Henaff, F. Gourmelon, A.T. Diaw, Evolution du trait de côte à Nouakchott (Mauritanie) de 1954 à 2001 par photo-interprétation. Norois, $\mathrm{n}^{\circ} 208,2008 / 3$, p. 11 - 27 (2008)

15. P. Durand, Approche méthodologique pour l'analyse de l'évolution des littoraux sableux par photointerprétation. Photo-Interprétation, n²000/12, p. 3-18. (2000)

16. E.H. Boak, I.L. Turner, Shoreline definition and detection: A review. Journal of coastal Research, vol. 21, n 4, p. 688-703. (2005)

17. E.R. Thieler, EA. Himmelstoss, JL. Zichichi, A. Ergul,. The Digital Shoreline Analysis System (DSAS) Version 4.0 - An ArcGIS Extension for Calculating Shoreline Change. Open-File report. US Geological Survey Report No. 2008- 1278,(2009) http://woodshole.er.usgs.gov/projectpages/dsas/versi on4/ 
18. R. Dolan, M.S. Fenster, S. J. Holme, Temporal Analysis of Shoreline Recession and Accretion. Journal of Coastal Research, Vol. 7, No. 3, pp. 723744, (1991).

19. F. Z. Salim, M. Y. El Habti, K. Lech-Hab Ben Hamman, A. Raissouni, A. El Arrim. Application of a Geomatics Approach for the Diachronic Study of the Meditterannean: Coastline Case of Tangier Bay. 